\title{
Shape Effect of Fractures on Intensity and Density of Discreet Fracture Networks
}

\author{
Akbar Esmaeilzadeh', Kurosh Shahriar ${ }^{1 *}$ \\ ${ }^{1}$ Department of Mining Engineering, \\ Faculty of Mining and Metallurgical Engineering, \\ Amir Kabir University of Technology \\ 424 Hafez Ave, Tehran, Iran, P.O.B. 159163-4311 \\ *Corresponding author, e-mail: k.shahriar@aut.ac.ir
}

Received: 06 January 2019, Accepted: 09 February 2019, Published online: 05 April 2019

\begin{abstract}
Fractures are amongst the most important factors determining the behavior of rock masses. The lack of direct access to the real fractures' distribution leads to the use of indirect methods for their study. The generation of the discrete fracture network is one of the most common indirect methods. Fractures' shape is one of the most important properties that the simulation of which is of great help in studying the fracture network. A wide range of shapes which include from infinite plates to elliptical shape have been suggested for the simulation of fractures. The present paper makes use of the data collected from the pumped-storage power plant and dam project in Roudbar, Lorestan Province, to provide circular and elliptical network of discrete fractures; moreover, the parameters as density, intensity and the real mean value of the length of the fracture traces have been used to evaluate the effect and accuracy of the selected shapes. Following the implementation of the proposed method, it was made clear that the elliptical discrete fracture network, with a mean error value of $13.5 \%$, outperforms the circular disk discrete fracture network, with a mean error value of $27.5 \%$; hence, it was found providing more accurate results for the description of the fractures network in the aforementioned region.
\end{abstract}

Keywords

DFN, elliptical fractures, density, intensity, Rudbar Lorestan

\section{Introduction}

Rock mass is used as the main material in the majority of the infrastructural projects like tunnels, caves and dams. In most of the engineering applications, the fractures existent in the rock mass alongside with the rock material, itself, is enumerated as an effective factor in the determination of the strength or hydraulic behavior of the rock structures [1]. In the studies of fracture network of the rock mass, there are ambiguous and uncertain aspects due to its complicacies rendering the rock mass behavior prediction a confusing task. One of the biggest problems which is exist in the study of fractures is the lack of direct access to them. The fracture residing in the heart of the rock mass does not allow its observation and exact and non-intermediated investigation. Under such conditions, the precise description of the fractures and the rock mass depends on the awareness of the fractures' statuses using indirect methods. Thus, the regeneration of fracture network is utilized as a strong tool for studying the fractures and the rock mass. One common method of studying the fracture behavior is the use of discrete fracture network. Random statistics processes are applied to generate the discrete fracture network. In this method, the required preliminary statistical parameters are extracted and used from the study population in the field via such features as outcrop, boreholes and other accessible levels. The statistics and probability sciences' theories provide appropriate solutions for overcoming the existing uncertainties in confrontation with various problems such as those posited in rock mechanics and geotechnics. Numerous factors influence the generation of the fracture network. One of the most important of these determinants is the fracture simulation shape. It is worth mentioning that the elliptical fractures are the most realistic shapes in fracture modeling [2].

Due to the capabilities of the analysis and assessment of the rock mass fracture behavior using discrete fracture network, many researchers have used it and reported its 
capabilities. Randomized modeling of the discrete fracture network stem from percolation studies the application domain of which was extended in rock engineering by some researchers, including Long et al. [3], Beacher [4], Andersson et al. [5], and Dershowitz and Einstein [6]. The discrete fracture network models have also been developed and employed by Robinson [7], Dershowitz [8], Long [9], Rouleau [10], Long and Witherspoon [11], Long and Billaux [12], Schwartz et al. [13], Schwartz and Smith [14], Long et al. [15], Lie et al. [16], Sanderson and Nixon [17], Cacas et al. [18], Dreuzy et al. [19], Elmo and Stead [20], Mauldon and Dershowitz [21], Wang [22], Dershowitz [23], Decker et al. [24], Zhang [25], Jin et al. [26], Jin et al. [27], Mayer and Stead [28] Gao and Kang [29], Vallejos [30], Zhang and Zhao [31], Lie [32], Lie et al. [33], Zou et al. [34], Wang [35], Lie and Wang [36], Tsang et al. [37], Lie et al. [38], Brzovic et al. [39].

The planar nature and the size of the fracture are the most important parameters influencing connectivity degree, permeability and stability of the rock mass [23-26, 40]. Based thereon, the determination of the shape and size of the fractures to the maximum possible extent has been extensively studied and drawn attentions during the recent decades $[40,41]$. Thus, it is necessary to have knowledge of the shape of the fractures during the qualitative and quantitative description of the rock mass. but the recognition of the fracture shape is blurry and insufficient because there is no $3 \mathrm{D}$ access to the rock mass and the relative recognition of the shape and size of the fractures is mostly limited to evidence-based interpretations.

Fracture shape as one of the most fascinating characteristics of the discontinuities has drawn the attentions of many researchers from long ago. In modeling the discrete fracture network, the selection of the fracture shape is of a great important. Zhang [42] and Zhang and Einstein [43], express that the shapes proposed for fracture simulation encompass a wide spectrum that ranges from the simplest state, to wit the infinite plate, to the most complex shapes like ellipses but, as it is asserted in the studies carried out in this regard, elliptical shape provides the best match with the majority of the extant statuses of the fractures in the rock mass. The first research work that attended to the fracture shape was done by Woodworth that was published in 1896 [43]. When working for Cambridge's argillites, he described the estimated shape of the fracture to be elliptical. Hodgson [44] organized Woodworth's works in 1961 and divided the fractures into two types, namely systematic and nonsystematic, and affirmed Woodworth's idea indicating the elliptical shape of the systematic fractures. Following the lead of Woodworth and Hodgson, Bankwitz described the fracture shapes to be circular to elliptical in 1965 and verified that the elliptical shapes provide a better approximation of the joints' shapes in most of the times [43]. Considering elliptical shapes for approximation of the fracture shape is not limited only to the above-mentioned works. Kulander et al. [45], Bahat [46], Petit [47], Weinberger [48], Bahat et al. [49] and Savalli and Engelder [50], as well, reported the fracture shapes to be elliptical. The fractures' elliptical shape has also been examined in the experiments. In line with this, Daneshy [51] investigated the shape of discontinuities induced by hydraulic fracturing and the results showed in the end that the discontinuities are elliptical in shape. Moriya et al. [52] investigated the propagation of the fractures in Bernborg Salt Mine and concluded the elliptical shape of the fractures.

\section{Site investigation}

Meanwhile generating the discrete fracture network using statistical data obtained from the analysis of the field characteristics of the fractures surveyed from the caverns of Roudbar's pumped-storage power plant, in Lorestan Province, the present paper considered the common elliptical and penny shapes for the simulation of the fractures so that the effect of the fracture shape on such parameters as density and intensity could be studied (Fig. 1). It is worth mentioning that there are only provided images pertaining to the elliptical modeling in the present study for preventing the enlargement of the paper volume and the circular models are also available that can be presented if requested.

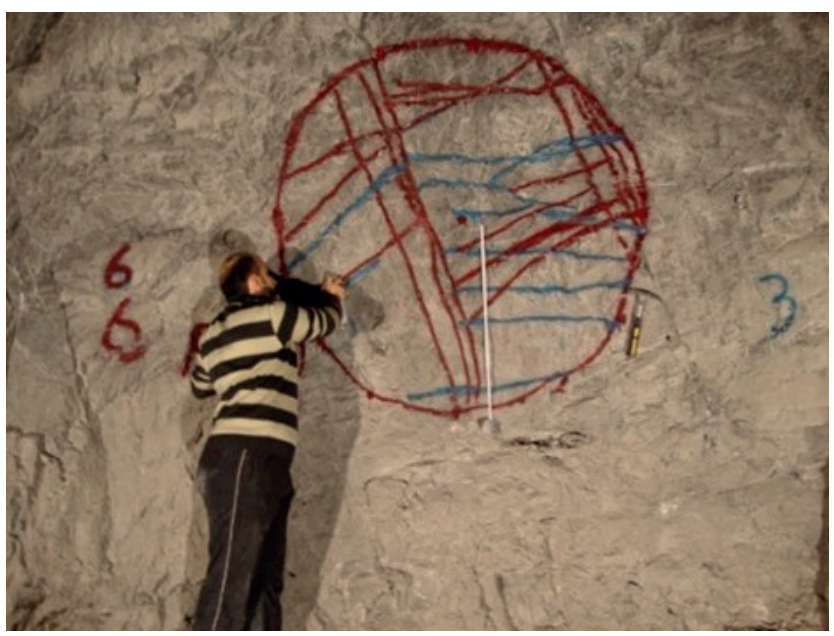

Fig. 1 Surveying Fractures of Rudbar Lorestan dam site using circular scan window 


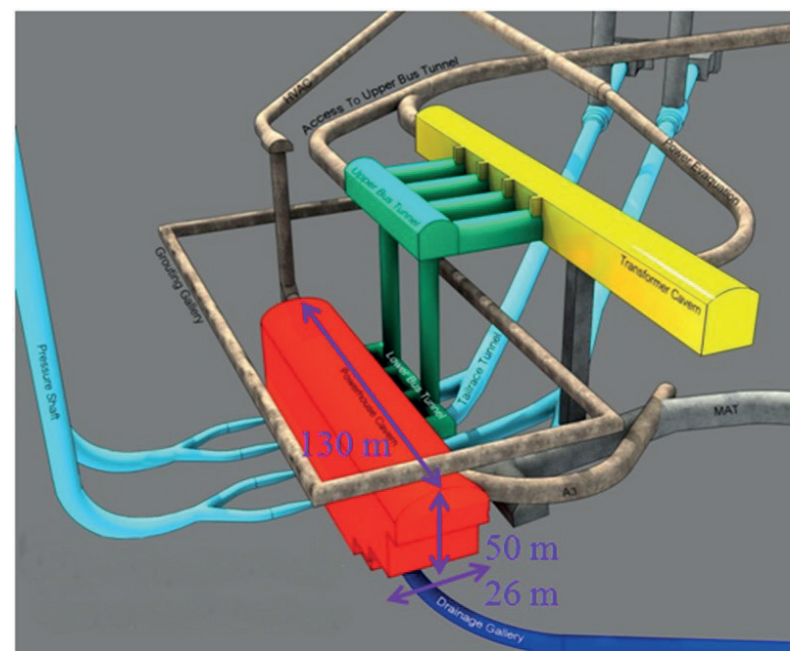

Fig. 2 layout of cavern of pumped-storage power plant project of Rudbar, Lorestan dam

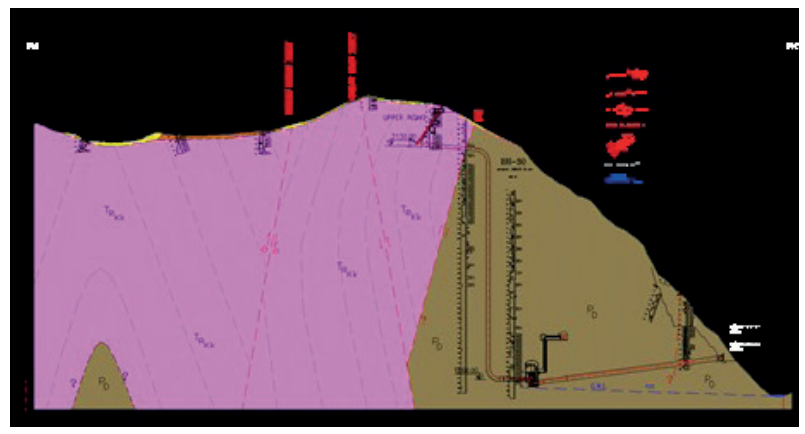

Fig. 3 Geology cross section of pumped-storage power plant project of Rudbar, Lorestan dam

The data obtained from the cavern of pumped-storage power plant project of Rudbar, Lorestan dam and was used in generation of discrete fracture networks. Rudbar, Lorestan pumped- storage plan located in Zagros high zone has very complicated tectonic conditions and numerous over thrust faults have formed high areas. The active faults of Saravan Baznavid and Chaleh Hatam are the most important faults in the site range. The carven of the power plant is located almost in the center of the anticline. The cavern has a length of 130 meters, a width of 26 meters and a height of 50 meters (Fig. 2), located in the Dalan Formation (end of the first geology period), with calcareous rock masses and dolomitic limestone of average thickness (Fig. 3). This project is under construction at the Rudbar, Lorestan Dam upstream, located $150 \mathrm{~km}$ west of Isfahan and $100 \mathrm{~km}$ south of Aligudarz city. The area of the project is located under the high sedimentary-structural zone (internal Zagros) (Fig. 4).

The data is obtained from the cavern by scanline and scan window surveying method, and its number reaches 627 fractures.

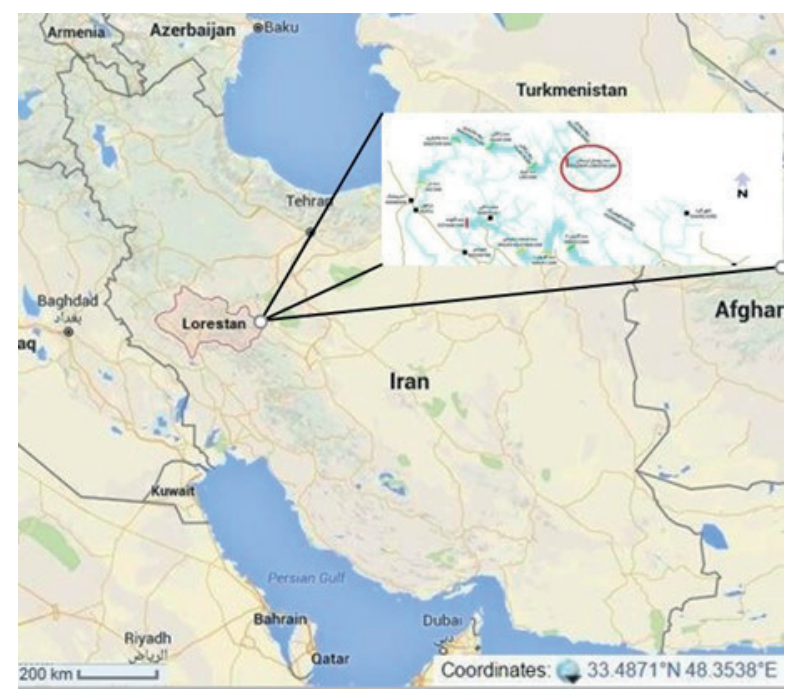

Fig. 4 Location of the study area

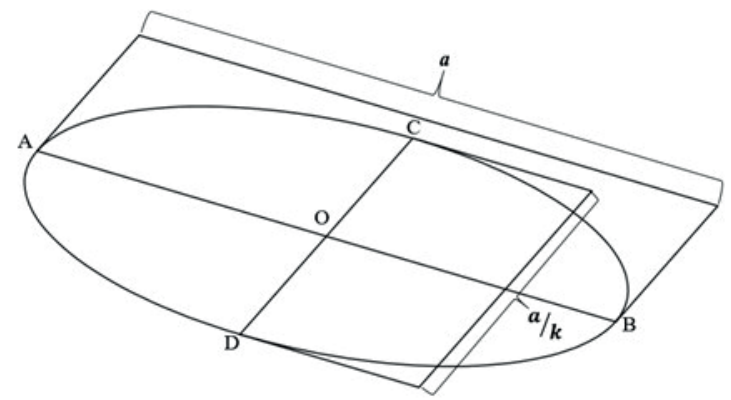

Fig. 5 Major and minor ellipse axis in elliptical discrete fractures network

\section{Materials and methodology}

\subsection{Elliptical discrete fracture network generation}

In the process of fracture simulation using elliptical disks, the ellipses' sizes are the most important indices taken into account. The major axes length of the ellipse (a) should be randomly estimated in the generation of the fracture existent in the studied rock mass alongside the random generation of the fracture center (Fig. 5).

The minor axes of the ellipse can be obtained via randomized generation of the large axes and through taking into consideration the ratio of the ellipse's axis. Thus, according to the aforementioned process, the length of the major axes of the ellipse is in fact the index determining the size of the elliptical fracture. To perform randomized generation of the ellipses' size (their major axis), a distribution function corresponding to the population of the real fracture size is needed to be used. To do so, the hypotheses assuming the disk-like nature of the fractures and the independency of the center and size of the disks from their spatial position are considered in the first stage to obtain the real probability distribution function of the trace length of 
the fractures $(f(l))$ following which the third moment of the probability distribution function $\left(E\left(l^{3}\right)\right)$ should be calculated. Based on the studies performed in this regard, the distribution function governing the fracture size is one of the following three: lognormal, exponential and gamma distribution functions. Considering one of the lognormal, negative exponential and/or gamma probability functions and based on the relations summarized in the table below, the mean $\left(\mu_{a}\right)$ and standard deviation $\left(\sigma_{a}\right)$ of the fracture size will be calculated. It has to be pointed out that, in Table (1) and Table (2), $\mu_{a}$ and $\sigma_{a}$ are the mean and standard deviation of the probability distribution function of the elliptical fracture sizes, and $\mu_{1}$ and $\sigma_{1}$ are the mean and standard deviation of the probability distribution function of the length of the trace of the real fractures, respectively.

To evaluate the quality of the proposed probability distribution function, the fourth moment of the probability distribution function of the fracture size $\left(E\left(a^{4}\right)\right)$ is computed to investigate the optimality of the selected distribution function's performance based on Eq. (1) as a result of which the best distribution function can be decided:

$$
\frac{E\left(a^{4}\right)}{E(a)}=\frac{16 E\left(l^{3}\right)}{3 \pi M^{3}} \text {. }
$$

Table 1 Calculation formulas of fractures mean size distribution using true fracture traces distribution function [53]

\begin{tabular}{lc}
\hline $\begin{array}{l}\text { Assumed Fracture size } \\
\text { distribution Function }\end{array}$ & Fracture size mean $\mu_{a}$ \\
\hline Lognormal & $\frac{128\left(\mu_{l}\right)^{3}}{3 \pi^{3} M\left[\left(\mu_{l}\right)^{2}+\left(\sigma_{l}\right)^{2}\right]}$ \\
Negative exponential & $\frac{2}{\pi M} \mu_{l}$ \\
Gamma & $\frac{64\left(\mu_{l}\right)^{2}-3 \pi^{2}\left[\left(\mu_{l}\right)^{2}+\left(\sigma_{l}\right)^{2}\right]}{8 \pi M \mu_{l}}$ \\
\hline
\end{tabular}

Table 2 Calculation formulas of fractures Standard deviation of size distribution using true fracture traces distribution function [53]

\begin{tabular}{lc}
\hline $\begin{array}{l}\text { Assumed Fracture size } \\
\text { distribution Function }\end{array}$ & Fracture size Standard deviation $\left(\sigma_{a}\right)^{2}$ \\
\hline Lognormal & $\frac{1536 \pi^{2}\left[\left(\mu_{l}\right)^{2}+\left(\sigma_{l}\right)^{2}\right]\left(\mu_{l}\right)^{4}-128^{2}\left(\mu_{l}\right)^{6}}{9 \pi^{6} M^{2}\left[\left(\mu_{l}\right)^{2}+\left(\sigma_{l}\right)^{2}\right]^{2}}$ \\
Negative exponential & $\left(\frac{2}{\pi M} \mu_{l}\right)^{2}$ \\
& $\left\{64\left(\mu_{l}\right)^{2}-3 \pi^{2}\left[\left(\mu_{l}\right)^{2}+\left(\sigma_{l}\right)^{2}\right]\right\} \times$ \\
Gamma & $\left\{3 \pi^{2}\left[\left(\mu_{l}\right)^{2}+\left(\sigma_{l}\right)^{2}\right]-32\left(\mu_{l}\right)^{2}\right\}$ \\
& $\frac{64 \pi^{2} M^{2}\left(\mu_{l}\right)^{2}}{}$ \\
\hline
\end{tabular}

In Eq. (1), $M$ is calculated from the Eq. (2):

$$
M=\frac{\sqrt{(\tan \beta)^{2}+1}}{\sqrt{k^{2}(\tan \beta)^{2}+1}} .
$$

In Eq. (2), $\beta$ is the angle between the major axis of the elliptical fracture and the direction of the fracture trace on the surveyed outcrop (Fig. 6).

When computing the probability distribution function of the fracture size, there is a need for having available the real distribution function of the fracture trace length for the obtaining of the mean value of which for a circular scan window, Eq. (3) can be applied:

$\hat{\mu}_{l}=\frac{\pi\left(\widehat{N}+\widehat{N}_{0}-\widehat{N}_{2}\right)}{2\left(\widehat{N}-\widehat{N}_{0}+\widehat{N}_{2}\right)} c$.

In the above relation, $\hat{N}$ is the total number of the trace of the appeared fractures in the scan window, $\hat{N}_{0}$ is the number of the traces featuring two obscured end and $\hat{N}_{2}$ is the number of the traces featuring to observable end; $c$ is the scan window radius. To calculate the standard deviation of the real distribution function of the trace length of the fractures, the trace length population covariance is firstly calculated as shown in the Eq. (4):

$$
\operatorname{COV}_{m}=\frac{\left(\mu_{l}\right)_{m}}{\left(\sigma_{l}\right)_{m}}
$$

Where, $\left(\mu_{\nu}\right)_{m}$ and $\left(\sigma_{\nu}\right)_{m}$ are the mean and standard deviation of the collected trace length values, respectively. Since a population's covariance is always a fixed value, the real standard deviation of the trace lengths can be computed from the Eq. (5) having determined the real mean values of the trace lengths beforehand:

$$
\sigma_{l}=\frac{\mu_{l}}{C O V_{m}} .
$$

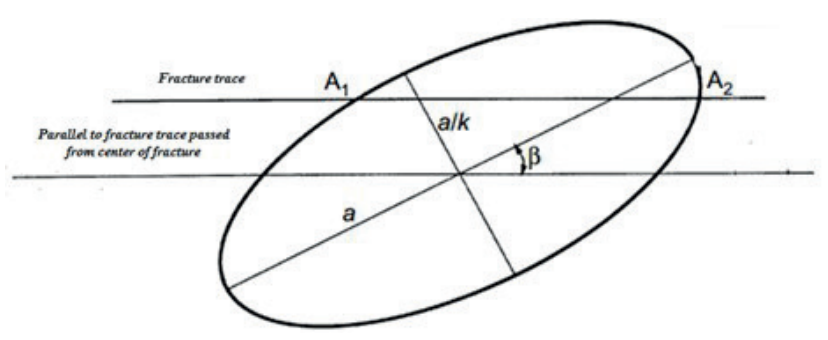

Fig. 6 Elliptical fracture simulation and tilt angle between ellipse major axis and line parallel to the facture trace which pass center of ellipse $(\beta)$ [53] 
Having the real mean and standard deviation of the trace lengths at hand and using the relations offered in Table 1, the mean and standard deviation of the probability distribution function governing the elliptical fracture size will be made available. The distribution function governing the trace lengths extracted based on the presumption that one of the gamma, lognormal and negative exponential distribution functions can be the objective function is investigated using chi square or Kolmogorov-Smirnov tests and/or other extant statistical tests [53].

\subsection{Comparisons parameters}

It is essential that the bitmap images have sufficient resolution to allow faithful reproduction. To study the effect of the fracture shape, $P_{20}$ parameters are applied as density and $P_{21}$ and $P_{32}$ parameters are applied as intensity parameters and the real mean of the fracture trace length, $\mu_{L}$, is used. Eqs. (6-8) demonstrate the calculation method of density and intensity of fractures in network:

$$
\begin{aligned}
& P_{20}=\frac{\text { Number of Trace Centers }}{\text { Sampling Area }}, \\
& P_{21}=\frac{\text { Lenght of fracture Trace }}{\text { Sampling Area }}, \\
& P_{32}=\frac{\text { Area of fractures }}{\text { Volume of Domain }} .
\end{aligned}
$$

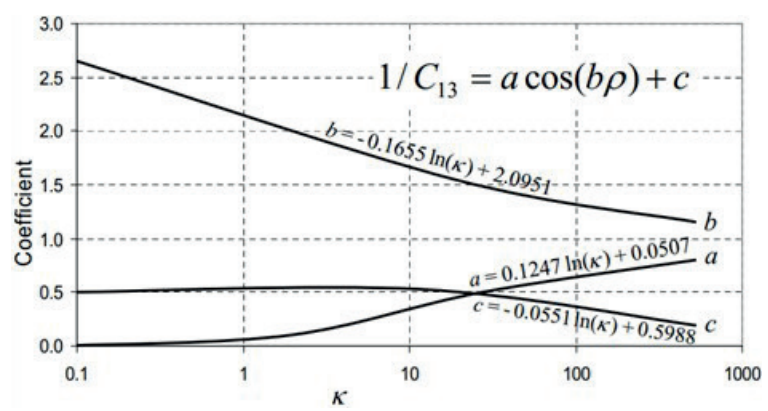

Fig. 7 Wang proposed graph for determining of $C_{31}$ for $P_{32}$ calculating [22]

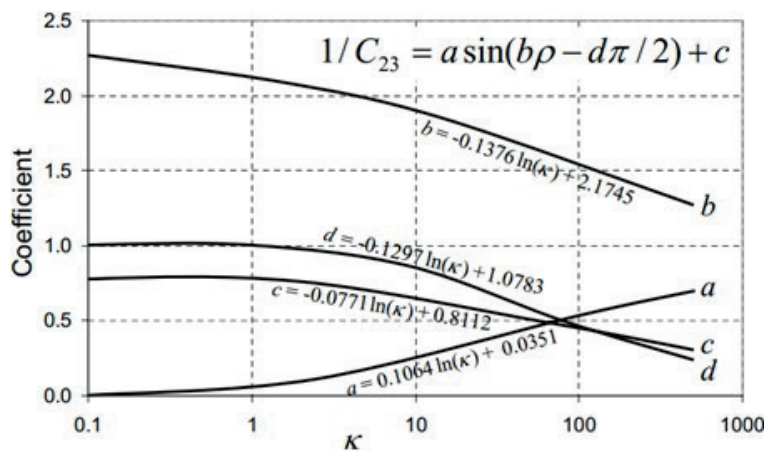

Fig. 8 Wang proposed graph for determining of $C_{32}$ for $P_{32}$ calculating [22]

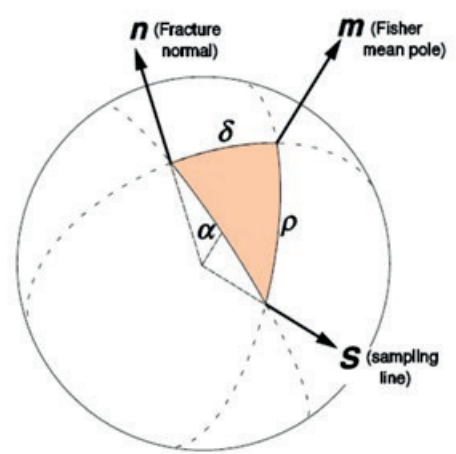

Fig. 9 illustration of Rho angle $(\rho)$ parameter [22]

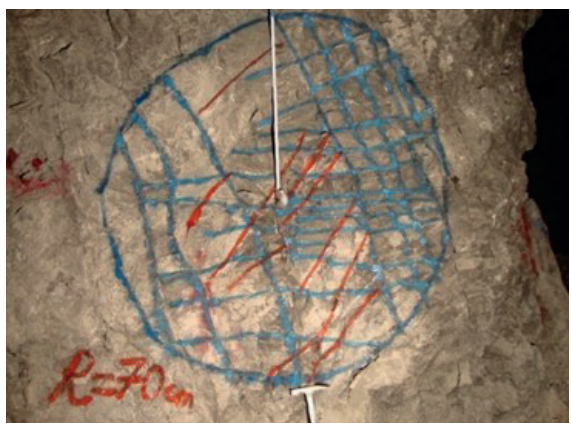

Fig. 10 Sample of circular scan window photo

Since it is highly important to calculate the parameters describing the fractures in three dimensions and also because it is not possible to directly determine the required parameters for their calculation, $P_{32}$ parameter is computed using the relation proposed by Wang. Due to the importance of $P_{32}$ parameter, on the one hand, and the lack of direct access thereto under real circumstances, Wang proposes the Eqs. (9-10) [22]:

$P_{32}=C_{31} P_{10}$

$P_{32}=C_{32} P_{21}$

In Eqs. (9-10), $C_{31}$ and $C_{32}$ depend on the fracture orientation and Fisher's constant and they both are obtained using the diagrams shown in Figs. 7 and 8 [22].

In Figs. 7 and $8, \rho$ is the spatial angle differential between the mean vector of the joint set and the vector parallel to the scan line (Fig. 9).

\subsection{Surveyed data}

To investigate the fractures' statuses in terms of the density and intensity of being jointed, nine circular scan windows are created. According to the trace length of the fractures, the scan windows' radii are set between half a meter and one meter. To perform exact determination of the fractures before surveying, the fracture surfaces were washed. Fig. 10 illustrates a sample of the created scan window. 
Table 3 Data obtained from circular scan window surveying

\begin{tabular}{lcccc}
\hline No & Scan window & $\begin{array}{c}\text { Surveyed } \\
\text { Plane } \\
\text { Orientation }\end{array}$ & Radius(m) & Density $\left(P^{20}\right)$ \\
\hline 1 & SWR1 & N26E & 0.7 & 9.10 \\
2 & SWL2 & N26E & 0.7 & 5.85 \\
3 & SWL3 & N26E & 0.8 & 4.98 \\
4 & SWGTL1 & S26W & 0.6 & 9.73 \\
5 & SWGTL2 & S26W & 0.6 & 7.08 \\
6 & SWP & S64E & 1 & 12.42 \\
7 & SWP1 & S64E & 0.55 & 14.74 \\
Mean & & & & 10.07 \\
\hline
\end{tabular}

Table 4 Intensity and density Data obtained from circular scan window surveying

\begin{tabular}{cccc}
\hline No. & Intensity $\left(P^{20}\right)$ & $\begin{array}{c}\text { Volumetric } \\
\text { Intensity }\left(P^{32}\right)\end{array}$ & $\begin{array}{c}\text { Real Mean trace } \\
\text { Length }\left(\mu_{L}\right)\end{array}$ \\
\hline 1 & 2.51 & 2.1 & 0.43 \\
2 & 6.71 & 3.22 & 0.47 \\
3 & 3.62 & 2.73 & 0.78 \\
4 & 3.16 & 3.4 & 0.55 \\
5 & 1.73 & 2.13 & 0.43 \\
6 & 5.07 & 4.16 & 0.72 \\
7 & 6.00 & 4.07 & 1.02 \\
Mean & 4.72 & 3.12 & 0.63 \\
\hline
\end{tabular}

Using the collected data from the circular scan windows, the density, intensity, the volumetric joint set intensity and the real mean of the fractures are calculated. Table 2 presents the results obtained from the data analysis obtained from circular scan window. These results will be utilized for the comparison of the performance of the created discrete fracture network using circular and elliptical fractures. It is noteworthy that the created circular windows are located on the perpendicular walls of the space created in the power plant's cavern ceiling in three different axes. The orientations of the sampled walls have been given in Table 3 and Table 4 .

\section{Results}

\subsection{Project cavern site elliptical discrete fracture network generation}

To generate the discrete fracture network, there is a need for access to certain data. The data required for the generation of discrete fracture network have been obtained from the collecting and analyzing of the field data of the dam project and power plant project in Roudbar, in Lorestan Province. Table 5 and Table 6 gives the parameters used in the generation of the separate fracture network.

Table 5 Statistical analysis result of Circular survey data

\begin{tabular}{lcccc}
\hline Joint Sets & Dip Direction $\left(^{\circ}\right)$ & $\operatorname{Dip}\left({ }^{\circ}\right)$ & K-Fisher \\
\hline \multirow{2}{*}{ First Set } & 123 & 60 & 17.3 \\
\multirow{2}{*}{ Second Set } & 280 & 46 & 9.5 \\
& Parents & 33 & 76 & 25.6 \\
\multirow{2}{*}{ Bedding } & Daughters & 29 & 73 & 10.4 \\
& & &
\end{tabular}

Table 6 Statistical analysis result of Circular survey data

\begin{tabular}{lccc}
\hline Joint Sets & $\begin{array}{c}\text { Mean Trace } \\
\text { Length }(\mathrm{cm})\end{array}$ & $\begin{array}{c}\text { S.D. of Trace } \\
\text { Length }(\mathrm{cm})\end{array}$ \\
\hline First Set & 64.1 & 53 \\
Second Set & & 66.5 & 53.4 \\
\cline { 3 - 4 } Bedding & Parents & 892 & 300 \\
& Daughters & 221.57 & 107.7 \\
\hline
\end{tabular}

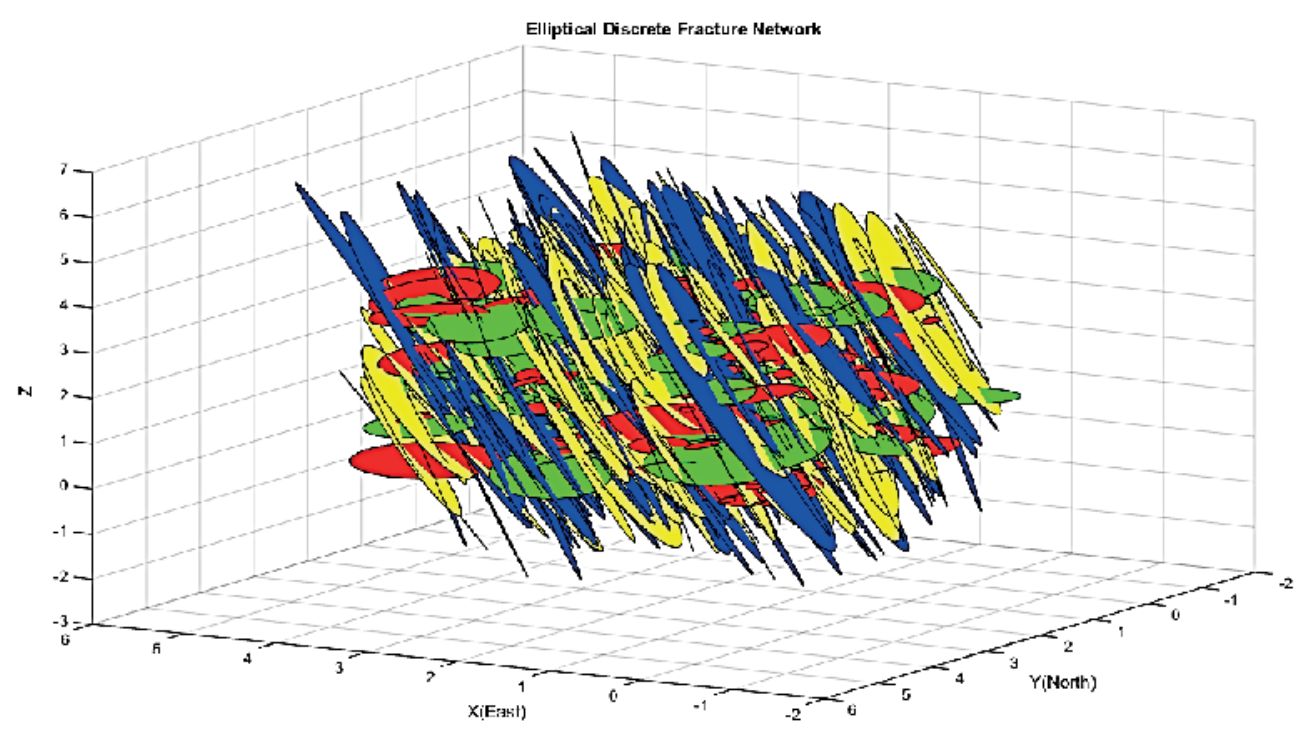

Fig. 11 Rudbar Lorstan project site Elliptical Discrete fracture network 
Table 7 Input data for generation Elliptical and Penney shape Discrete Fracture networks

\begin{tabular}{|c|c|c|c|c|c|c|c|c|}
\hline \multirow{2}{*}{$\begin{array}{l}\text { Simulation number } \\
\text { Fracture Sets }\end{array}$} & \multicolumn{4}{|c|}{1} & \multicolumn{4}{|c|}{2} \\
\hline & Joint Set 1 & Joint set 2 & Bedding & Daughters & Joint Set 1 & Joint set 2 & Bedding & Daugthers \\
\hline Fracture orintation $(\beta / \alpha)$ & $60 / 123$ & $46 / 280$ & $76 / 33$ & $73 / 29$ & $60 / 123$ & $46 / 280$ & $76 / 33$ & $73 / 29$ \\
\hline $\begin{array}{l}\text { P10 (linear intencity) } \\
(1 / \mathrm{m})\end{array}$ & 1.25 & 1.25 & 1 & 1 & 1.25 & 1.25 & 1 & 1 \\
\hline Shape & Circular & Circular & Circular & Circular & Elliptical & Elliptical & Elliptical & Elliptical \\
\hline $\begin{array}{l}\text { Trace length disribution } \\
\text { (pdf) }\end{array}$ & Lognormal & Lognormal & Lognormal & Lognormal & Lognormal & Lognormal & Lognormal & Lognormal \\
\hline $\begin{array}{l}\text { mean trace length } \mathrm{cm}) / \\
\text { standard deviation }(\mathrm{m})\end{array}$ & $64.1 / 53$ & $66.5 / 53.4$ & $892 / 300$ & $221 / 107.7$ & $64.1 / 53$ & $66.5 / 53.4$ & $892 / 300$ & $221 / 107.7$ \\
\hline $\begin{array}{l}\text { Diameter }(\mathrm{m}) / \mathrm{axis} \\
\text { ration }\end{array}$ & $0.74 / 1$ & $0.69 / 1$ & $1.4 / 1$ & $1.69 / 1$ & $0.74 / 0.32$ & $0.69 / 0.17$ & $1.4 / 0.86$ & $1.69 / 0.93$ \\
\hline$\rho$ angle / K-fisher & $84 / 17.3$ & $78.6 / 9.5$ & $15.6 / 25.6$ & $20 / 10.4$ & $84 / 17.3$ & $78.6 / 9.5$ & $15.6 / 25.6$ & $20 / 10.4$ \\
\hline Block volume & \multicolumn{4}{|c|}{$100 * 100 * 100$} & \multicolumn{4}{|c|}{$100 * 100 * 100$} \\
\hline
\end{tabular}

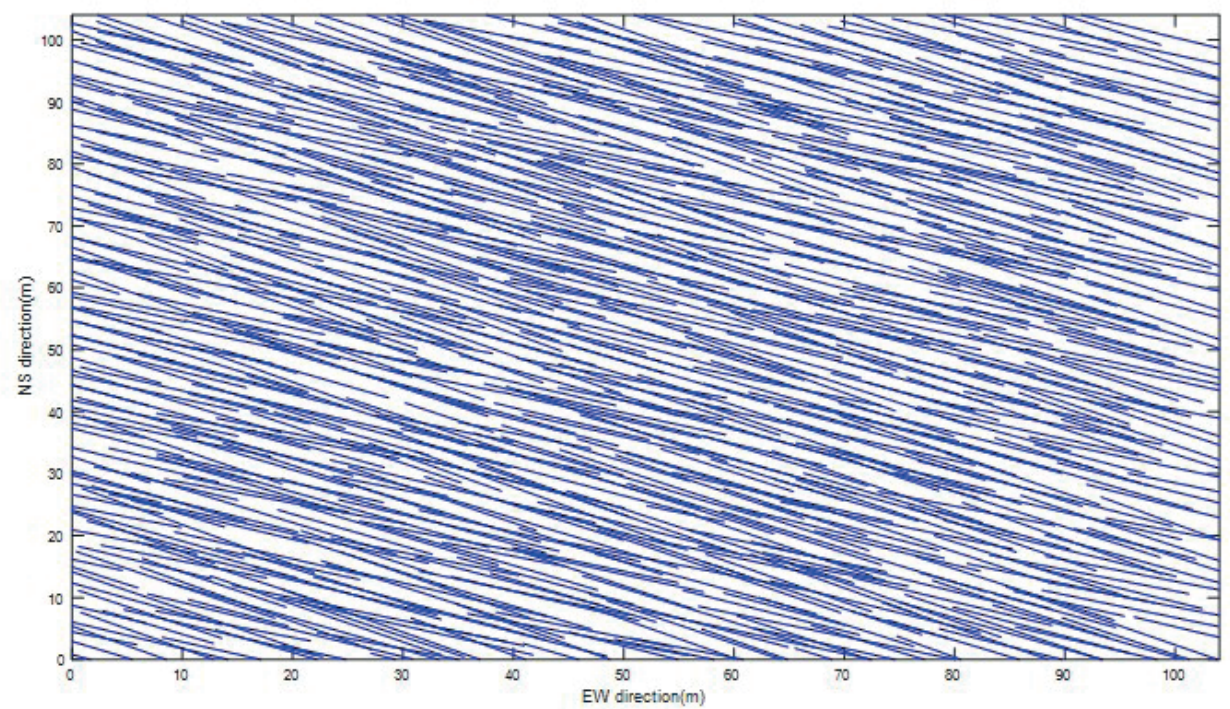

Fig. 12 Rudbar lorstan project site Elliptical Discrete fracture network

To investigate the effect of fracture shape selection on the discrete fracture network performance, two discrete fracture networks were generated using characteristics shown in Table 7.

It is worth mentioning that the inputs for the generation of the discrete fracture network have been summarized in Table 7. In fact, these are the results of the statistical analysis performed on the data collected from the cavern sites of the dam and power plant projects in Roudbar, Lorestan province. In generation of the fracture network, the other parameters like the generated fractures dip and dip direction and, finally, the number of the generated fractures was considered identical in the investigation of the effect of shape and for the purpose of preventing the effect of the other factors. Images presented in Fig. 11 display the elliptical discrete fracture network.

\subsection{Elliptical discrete fracture network validating}

After the generation of the discrete fracture network, it has to be validated so that its accuracy can be ascertained. To do so, certain cross sections are passed orthogonally and horizontally and the dip and dip direction of the generated traces is compared with the real dip and dip direction of the fractures to figure out the network performance accuracy. In doing so, horizontal cross sections aligned east-westward and north-southward were passed through the network for the investigation of the fractures' dip directions and orthogonal cross sections perpendicular to the fracture dip direction were passed through the network to investigate the fracture dips. The generated traces and the comparisons of resulted numerical values are as follows. 


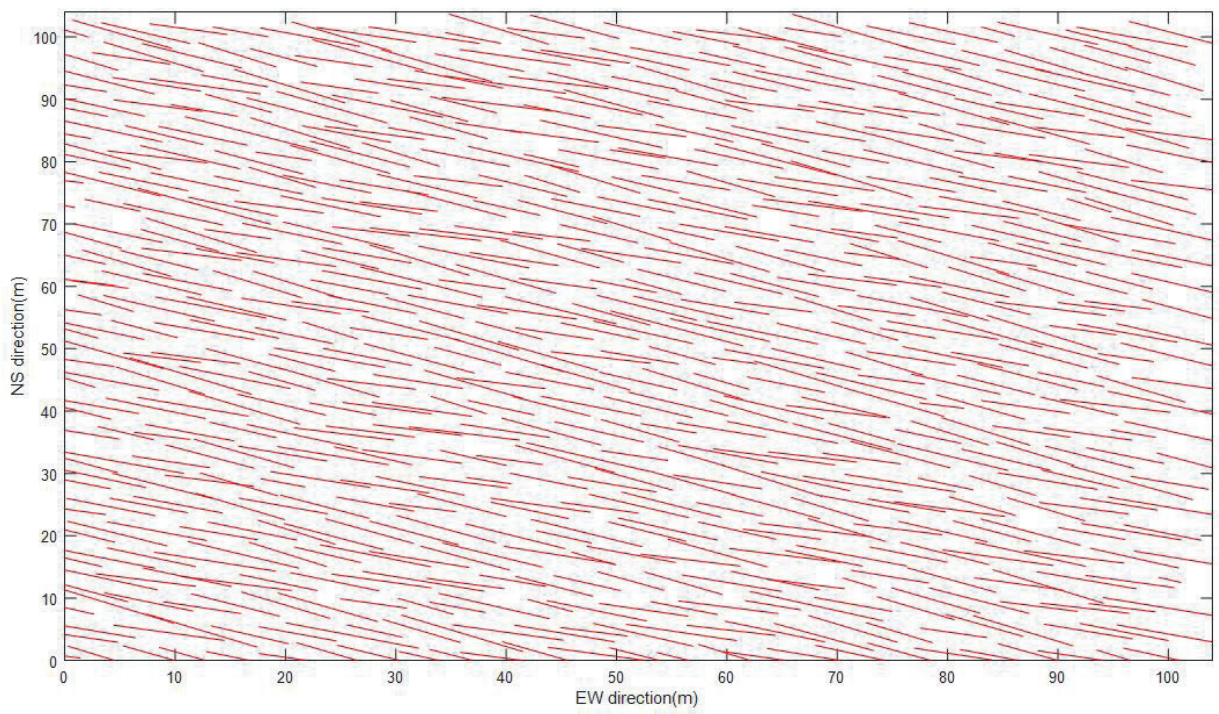

Fig. 13 Daughter Bedding fracture traces on horizontal survey plane

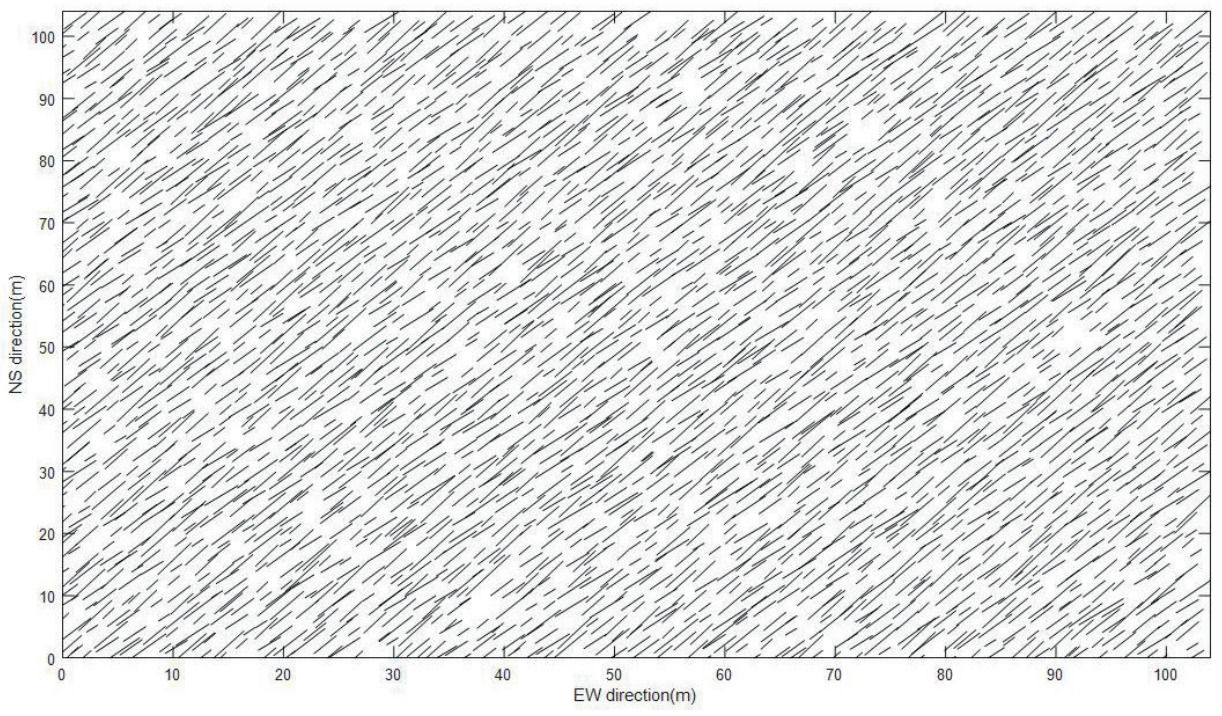

Fig. 14 Joint Set No.1 fracture traces on horizontal survey plane

To validate the generated networks in the first stage, the mean comparison of the traces strikes and the dip of the fractures generated as a result of the fractures' intersections with the passed cross section are undertaken. In this stage, the traces of each of the four joint sets are separately investigated in their intersections with the orthogonal and horizontal survey planes. It has to be pointed out that the horizontal survey plane is used for the investigation of the strike and the orthogonal survey plane is used to investigate dip direction of each joint set so that the dip of the generated fractures could be evaluated. Figs. 12, 13, 14 and 15 exhibit the horizontal cross-sections of the fourfold joint set.

According to Fig. 12, it is clear that the mean strike of the generated fractures in the network is nearly in S57E direction that is indicative of a good match with the real conditions. The calculation of the strike of observable traces in Fig. 12 and its match with stereo net, as well, are reflective of the strike of this joint set along S63E orientation which is indicative of an acceptable match with the real conditions of this joint set.

Fig. 13 demonstrates the strike of the joint set pertaining to the daughter fractures. This joint set features similar layering conditions in terms of dip and dip direction hence it is expected to have a strike parallel to the bedding. Based on the statuses of the traces pertaining to this stratification in the horizontal survey plane, the mean value of the strike of this joint set is almost in S61E direction which is reflective of a high match with reality. The mean value obtained for this joint set based on the generated network is equal to S53E. 


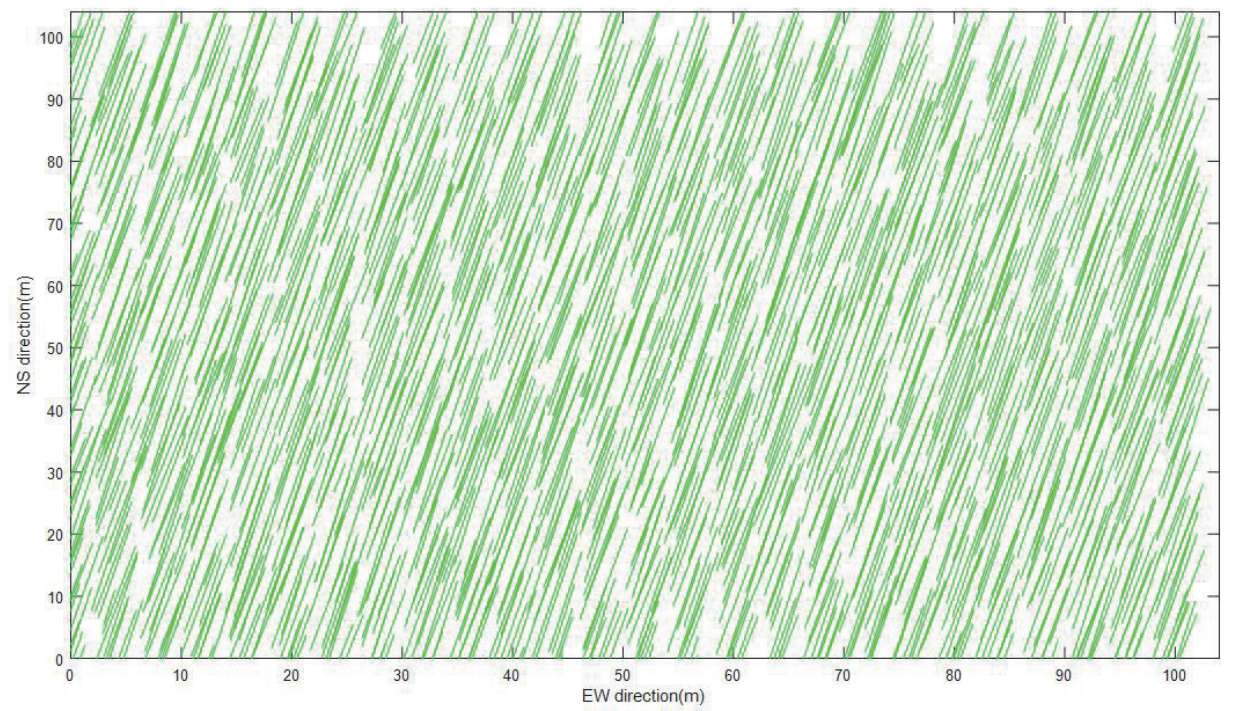

Fig. 15 Joint set No. 2 fracture traces on horizontal survey plane



Fig. 16 Parent Bedding fracture traces on Vertical survey plane

Fig. 14 shows the dip direction of joint set No. 1. Based on the collected data and the related statistical analyses, the joint set is expected to be had strike along N33E orientation. Considering Fig. 14 and based on the dip directions, it can be seen that the strike of the joints in this set are on average along the same orientation obtained for the collected data and hence a good match between the generated model and the nature of this joint set can be discerned. Of course, it has to be mentioned based on the calculations that the strike of this joint set is equal to N38E which is considered an acceptable error for a prediction model.

Fig. 15 displays the strike of the joint set No. 2 that has to be aligned along N10W orientation. According to the status of the data pertinent to this joint set, their strike is almost highly approximated to the strike of the joint set
No. 1 and Fig. 15 confirms the same point. On the other hand, according to the status and orientation of the joints and their strike, a good match was found with the results obtained from the relevant field data. For this joint set, as well, the calculations are reflective of N4W stretch which is again not suggestive of a significant error.

Figs. 16, 17, 18 and 19 illustrate the orthogonal crosssections created in the elliptical discrete fracture network model and, as can be seen, they have been crossed for the study of the fracture dips in a perpendicular to the strike of fracture set.

Fig. 16 demonstrates the vertical cross-section of the elliptical fractures generated for the parent bedding. According to the pass direction of the survey plane (N33E), the trace dips are indicative of the fracture dips values. 


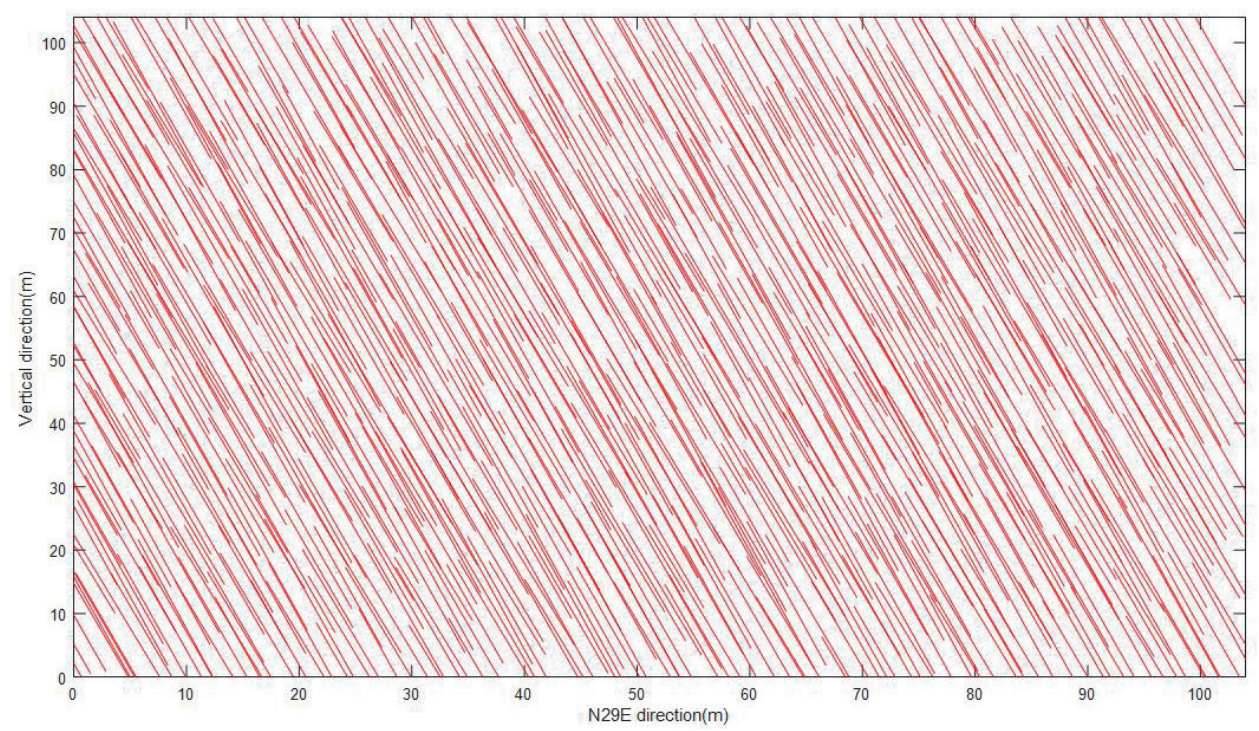

Fig. 17 Daughters Bedding fracture traces on vertical survey plane

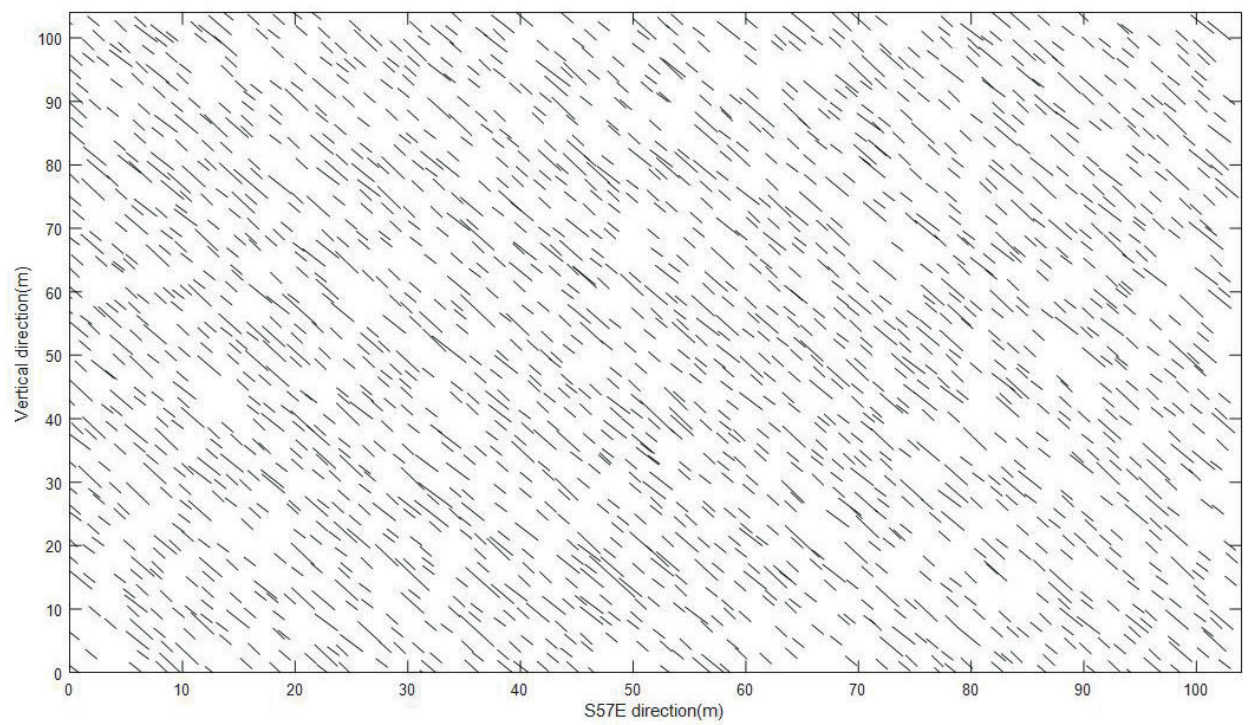

Fig. 18 Joint Set No. 1 fracture traces on vertical survey plane

Based on Fig. 16, it is evident that the mean fracture dip is close to the measured real dip, $76^{\circ}$. The calculated fracture dip value of this joint set has been obtained equal to $74^{\circ}$ using the survey plane.

As for the daughter bedding joint set, as well, a good match is observable in Fig. 17 between the dip of the generated fractures and the real dip surveyed for this joint set. While the dip of this set of joints is close to the parent bedding dip, Fig. 17 confirms the same reality and shows a good match between the generated fracture model and the reality of the joint set. It is noteworthy that the real dip value of this joint set is equal to $73^{\circ}$ which is only two degrees different from the dip calculated from the orthogonal survey plane, $75^{\circ}$.
Fig. 18, as well, presents the results of passing the orthogonal survey plane vertical to the strike of the joint set No. 1; the dip status of the joint set can also be seen. In Fig. 18, the mean value of the fractures' dips has been computed equal to $65^{\circ}$ which is reflective of a good match with the real slope of the joint set. It has to be noted that the real dip value of the joint set is equal to $60^{\circ}$.

The dip of the joint set No. 2 is equal to $46^{\circ}$. The dip of the joint set can be revealed through passing the orthogonal survey plane perpendicular to the joint set strike (Fig. 19). The dip of this joint set has been estimated equal to $43^{\circ}$ with the calculation of the dip mean of the joint set from the obtained cross-section which is indicative of the high match of the generated model to the real conditions of the joint set. 
Table 8 Comparison of dip and dip direction of generated DFN and surveyed data.

\begin{tabular}{lccccc}
\hline Joint set & Real Dip Direction & $\begin{array}{c}\text { Calculated Dip } \\
\text { Direction(DFN) }\end{array}$ & $\begin{array}{c}\text { Calculation } \\
\text { Error(\%) }\end{array}$ & $\begin{array}{c}\text { Real Dip } \\
\text { Calculated Dip } \\
(\text { DFN) }\end{array}$ & $\begin{array}{c}\text { Calculation } \\
\text { Error(\%) }\end{array}$ \\
\hline Bedding & 123 & 127 & 2.7 & 76 & 3.1 \\
Daughter & 119 & 117 & 2.6 & 73 & 75 \\
No. 1 & 213 & 218 & 7.7 & 60 & 65 \\
No.2 & 10 & 4 & 7 & 46 & 43 \\
\hline
\end{tabular}

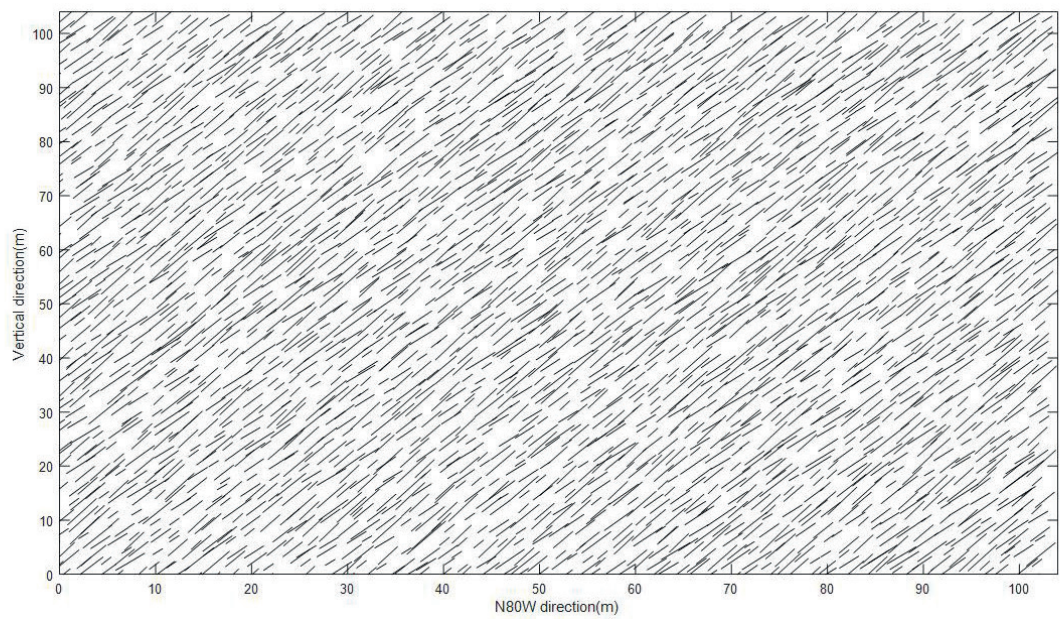

Fig. 19 Joint set No.2 fracture traces on Vertical survey plane

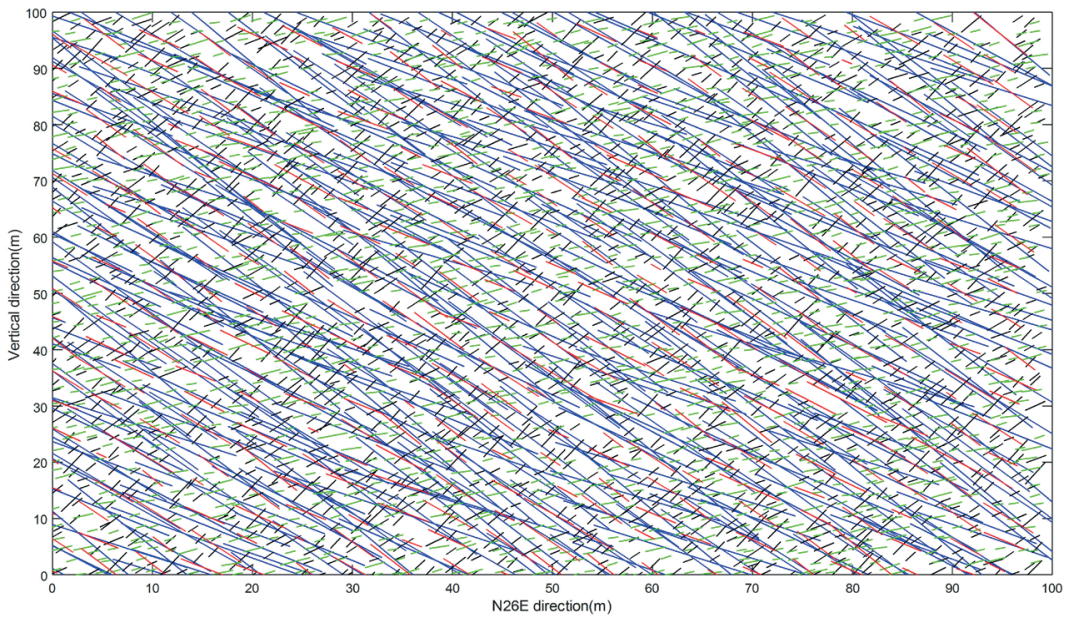

Fig. 20 generated 2-D Discrete fracture network

Table 8 depicts the real dip and dip direction values pertaining to the joint sets as well as the values calculated using the survey plane generated in the discrete fracture network along with their errors.

\section{Study of fracture shape selection effect}

The networks have been generated in dimensions that they could provide for a good coverage of the studied region in terms of size. The reason for the selection of these dimensions for the creation of fracture network is creation of match between the surveyed regions in the caverns and the location of circular window creation in the cross-sections of the generated fracture because the next stage considers the exact geometrical reflection of the studied region on the fracture network to estimate them with a good precision.

After the generation of the fracture network, the orthogonal cross-sections were created for the investigation of the network's accuracy and the effect of its shape on the fractures' behaviors considering the orientation of the walls surveyed in the cavern in such a manner that they provide for a match with the surveyed walls in terms of strike and slope. Fig. 20 demonstrates a sample of cross-sections created in the axes matching with the extracted axes. 

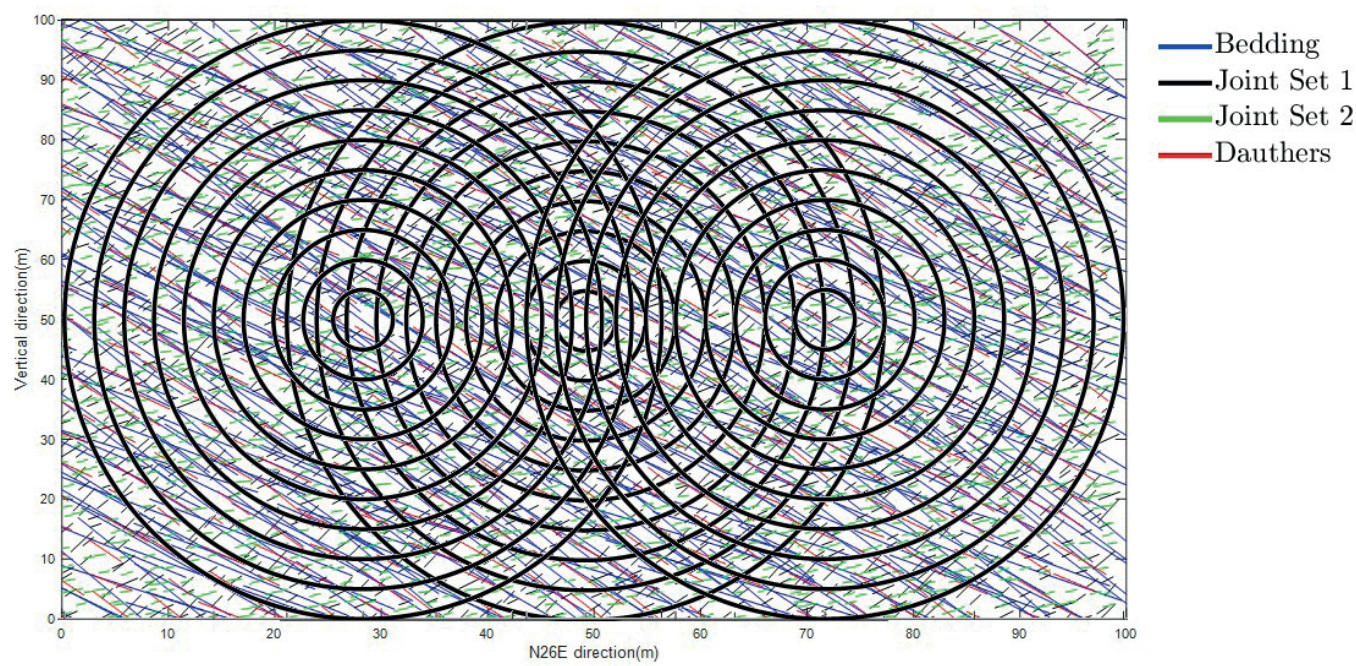

Fig. 21 Circular scan window for determination of model comparison parameters

Table 9 Comparison Parameters Value obtained from Elliptical and Circular discrete fracture network

\begin{tabular}{|c|c|c|c|c|c|c|c|c|}
\hline \multirow{2}{*}{$\begin{array}{l}\text { Plane } \\
\text { Orientation }\end{array}$} & \multicolumn{2}{|c|}{$\operatorname{Density}\left(P_{20}\right)$} & \multicolumn{2}{|c|}{$\operatorname{Intensity}\left(P_{21}\right)$} & \multicolumn{2}{|c|}{ Volumetric Intensity $\left(P_{32}\right)$} & \multicolumn{2}{|c|}{ Real Mean trace Length $\left(\mu_{L}\right)$} \\
\hline & Circular & Elliptical & Circular & Elliptical & Circular & Elliptical & Circular & Elliptical \\
\hline $\mathrm{N} 26 \mathrm{E}$ & 5.19 & 9.31 & 2.15 & 3.45 & 2.29 & 3.3 & 0.37 & 0.45 \\
\hline S26W & 6.06 & 5.23 & 3.58 & 3 & 4.22 & 3.41 & 0.68 & 0.62 \\
\hline S64E & 10.32 & 18.21 & 4.16 & 4.57 & 6.11 & 5.03 & 1.35 & 0.64 \\
\hline Mean & 7.19 & 10.91 & 3.30 & 3.67 & 4.21 & 3.91 & 0.8 & 0.57 \\
\hline
\end{tabular}

Table 10 Comparison of calculated parameters from generated discrete fracture networks and surveyed values

\begin{tabular}{lccccc}
\hline & Measured & \multicolumn{2}{c}{ DFN (disc fractures) } & \multicolumn{2}{c}{ DFN (elliptical fractures) } \\
& Value & Value & Error (\%) & Value & Error (\%) \\
\hline$\mu \_1$ & 0.63 & 0.8 & 27 & 0.57 & 10 \\
P_20 & 10.07 & 7.19 & 29 & 10.91 & 8 \\
P_21 & 4.11 & 3.30 & 19 & 3.67 & 11 \\
P_32 & 3.12 & 4.21 & 35 & 3.91 & 25 \\
Mean & & & & 13.5 \\
\hline
\end{tabular}

To calculate the selected parameters for the comparison of the shape effects, as shown in Fig. 21, a number of circular scan windows placed on the created $2 \mathrm{D}$ fracture network have been used. The reason for selecting the circular scan window, besides the aforesaid advantages mentioned in various resources such as the absence of the effect of the fracture orientation thereon, is the match between the scan methods and the study of the fracture status under real sampling conditions with the constructed models. In this stage, in order to provide for maximization of the limited coverage of the network, the circular scan windows have been created with various diameters and centrality of three different points. After matching the circular scan windows as demonstrated in Fig. 21, the methods proposed in the methodology section were applied to calculate the comparison parameters of each circular scan window following which normalization was carried out for the elimination of the scan window size effect in respect to its area and, in the end, the mean values of the intended parameters were obtained. The process has been repeated for both the circular and elliptical networks. Due to the number of the scan windows (30 windows in all three directions), Table 9 shows the mean values of the calculated parameters for the scan windows in each orientation.

In order to accuracy and performance study of circular and elliptical generated network, after calculation of comparisons parameters mean value of various surveyed direction, overall mean value of comparisons parameters was obtained for each network. Table 10 shows mean error values of each network for comparisons parameters. 


\section{Conclusions}

The precise recognition of the fractures and the study of various types of their properties play a crucial role in the study of the rock mass behavior. Due to the lack of direct access to the fractures hidden in the heart of the rock mass, the discrete fracture modeling based on the statistical data obtained from the real fracture statuses is deemed a common method. One of the most important parameters involved in the generation of discrete fracture network is the selection of the fracture shape. In the majority of the studies carried out in this study area, the fractures are simulated in the form of circular disks due to their simplicity of the analysis. But, as it is understood from the evidences and studies by the other researchers, the tendencies are higher towards the creation of the asymmetrical shapes for the fractures due to the emergence of mostly asymmetrical factors in the formation of the fracture. Thus, ellipse is the most optimum possible shape for the description of the fractures as opined

\section{References}

[1] Xu, C., Dowd, P. "A new computer code for discrete fracture network modelling", Computers \& Geosciences, 36(3), pp. 292-301, 2010. https://doi.org/10.1016/j.cageo.2009.05.012

[2] Lei, Q., Latham, J.-P., Xiang, J., Tsang, C.-F., Lang, P., Guo, L. "Effects of geomechanical changes on the validity of a discrete fracture network representation of a realistic two-dimensional fractured rock", International Journal of Rock Mechanics and Mining Sciences, 70, pp. 507-523, 2014.

https://doi.org/10.1016/j.ijrmms.2014.06.001

[3] Long, J. C. S., Remer, J. S., Wilson, C. R., Witherspoon, P. A. "Porous media equivalents for networks of discontinuous fractures", Water Resources Research, 18(3), pp. 645-658, 1982. https://doi.org/10.1029/WR018i003p00645

[4] Baecher, G. B. "Statistical analysis of rock mass fracturing", Journal of the International Association for Mathematical Geology, 15(2), pp. 329-348, 1983. https://doi.org/10.1007/bf01036074

[5] Andersson, J., Shapiro, A. M., Bear, J. "A Stochastic Model of a Fractured Rock Conditioned by Measured Information", Water Resources Research, 20(1), pp. 79-88, 1984. https://doi.org/10.1029/WR020i001p00079

[6] Dershowitz, W. S., Einstein, H. H. "Characterizing rock joint geometry with joint system models", Rock mechanics and rock engineering, 21(1), pp. 21-51, 1988. https://doi.org/10.1007/bf01019674

[7] Robinson, P. C. "Connectivity, flow and transport in network models of fractured media", Phd Dissertation, University of Oxford, 1984. [online] Available at: https://ora.ox.ac.uk/objects/uuid:c61bf73bb794-49d0-b644-e5429138b953 [Accessed: 02.04.2019]

[8] Dershowitz, W. S. "Rock joint systems", Phd Dissertation, Massachusetts Institute of Technology, 1984. [online] Available at: https://ci.nii.ac.jp/naid/10007462037/ [Accessed: 02.04.2019] by the majority of the researchers. The present paper considered an elliptical fracture shape and generated a discrete fracture network and parametrically compared it with the network created for the circular fractures. After the created network was validated, such parameters as $P_{20}, P_{21}, P_{32}$ and $\mu_{L}$ were applied to compare the precision of both of these networks. The result of the comparison of the foresaid parameters for both of the networks created using real values obtained from the field studies is indicative of the elliptical network's higher match as compared to the circular network. Although, the two networks are only approximate methods of studying the hidden behavior of the fractures, the results of the current research paper confirm the more precision of the elliptical simulation of the fractures and the results obtained from the elliptical discrete fracture network have been shown more acceptable and closer to reality. Of course, one should not forget that both of the models are prone to errors in contrast to real state.

[9] Long, J. C. S. "Investigation of equivalent porous medium permeability in networks of discontinuous fractures", Lawrence Berkeley Lab., Berkeley, CA, USA, Rep. LBL-16259, 1983. [online] Available at: https://www.osti.gov/biblio/5472384 [Accessed: 02.04.2019]

[10] Rouleau, A. "Statistical characterization and numerical simulation of a fracture system-application to ground water flow in the stripa granite", Phd Dissertation, University of Waterloo, 1985. [online] Available at: https://elibrary.ru/item.asp?id=7435394 [Accessed: 02.04.2019]

[11] Long, J. C. S., Witherspoon, P. A. "The relationship of the degree of interconnection to permeability in fracture networks", Journal of Geophysical Research: Solid Earth, 90(B4), pp. 3087-3098, 1985. https://doi.org/10.1029/JB090iB04p03087

[12] Long, J. C. S., Billaux, D. M. "From field data to fracture network modeling: an example incorporating spatial structure", Water Resources Research, 23(7), pp. 1201-1216, 1987. https://doi.org/10.1029/WR023i007p01201

[13] Schwartz, F. W., Smith, L., Crowe, A. S. "A stochastic analysis of macroscopic dispersion in fractured media", Water Resources Research, 19(5), pp. 1253-1265, 1983. https://doi.org/10.1029/WR019i005p01253

[14] Schwartz, F. W., Smith, L. "A continuum approach for modeling mass transport in fractured media", Water Resources Research, 24(8), pp. 1360-1372, 1988. https://doi.org/10.1029/WR024i008p01360

[15] Long, J. C. S., Karasaki, K., Davey, A., Peterson, J., Landsfeld, M., Kemeny, J., Martel, S. "An inverse approach to the construction of fracture hydrology models conditioned by geophysical data: An example from the validation exercises at the Stripa Mine", International Journal of Rock Mechanics and Mining Sciences \& Geomechanics Abstracts, 28(2-3), pp. 121-142, 1991. https://doi.org/10.1016/0148-9062(91)92162-R 
[16] Lei, Q., Latham, J.-P., Tsang, C.-F. "The use of discrete fracture networks for modelling coupled geomechanical and hydrological behaviour of fractured rocks", Computers and Geotechnics, 85, pp. 151-176, 2017.

https://doi.org/10.1016/j.compgeo.2016.12.024

[17] Sanderson, D. J., Nixon, C. W. "The use of topology in fracture network characterization", Journal of Structural Geology, 72, pp. 55-66, 2015 https://doi.org/10.1016/j.jsg.2015.01.005

[18] Cacas, M. C., Ledoux, E., de Marsily, G., Tillie, B., Barbreau, A., Durand, E., Feuga, B., Peaudecerf, P. "Modeling fracture flow with a stochastic discrete fracture network: calibration and validation: 1 . The flow model", Water Resources Research, 26(3), pp. 479-489, 1990. https://oi.org/10.1029/wr026i003p00479

[19] de Dreuzy, J.-R., Davy, P., Bour, O. "Hydraulic properties of two-dimensional random fracture networks following a power law length distribution: 1. Effective connectivity", Water Resources Research, 37(8), pp. 2065-2078, 2001. https://doi.org/10.1029/2001WR900011

[20] Elmo, D., Stead, D. "An integrated numerical modelling-discrete fracture network approach applied to the characterisation of rock mass strength of naturally fractured pillars", Rock Mechanics and Rock Engineering, 43(1), pp. 3-19, 2010. https://doi.org/10.1007/s00603-009-0027-3

[21] Mauldon, M., Dershowitz, W. S. "A multi-dimensional system of fracture abundance measures", Abstracts with Programs - Geological Society of America 32(7), 2000. [online] Available at: https://eurekamag.com/research/029/684/029684769.php [Accessed: 02.04 2019]

[22] Wang, X. "Stereological interpretation of rock fracture traces on borehole walls and other cylindrical surfaces", Doctoral Dissertation, Virginia Polytechnic Institute and State University, 2005. [online] Available at: http://hdl.handle.net/10919/29105 [Accessed: 02.042019]

[23] Dershowitz, B., LaPointe, P., Eiben, T., Wei, L. "Integration of Discrete Feature Network Methods with Conventional Simulator Approaches", In: SPE Annual Technical Conference and Exhibition, New Orleans, Louisiana, USA, 1998, pp. 351-360. https://doi.org/10.2118/49069-MS

[24] Decker, J. B., Mauldon, M., Wang, X. "Real-time determination of fracture size and shape using trace data on tunnel walls", Tunnelling and Underground Space Technology, 21(3-4), 2006. https://doi.org/10.1016/j.tust.2005.12.012

[25] Zhang, L. "Drilled shafts in rock, Analysis and design", 1st ed., CRC Press, London, United Kingdom, 2004. https://doi.org/10.1201/9780203024423

[26] Jin, W., Gao, M., Zhang, R., Zhang, G. "Analytical expressions for the size distribution function of elliptical joints", International Journal of Rock Mechanics and Mining Science, 70, pp. 201-211, 2014. https://doi.org/10.1016/j.ijrmms.2014.04.017

[27] Jin, W., Gao, M., Yu, B., Zhang, R., Xie, J., Qiu, Z. "Elliptical fracture network modeling with validation in Datong Mine, China", Environmental Earth Sciences, 73(11), pp. 7089-7101, 2015. https://doi.org/10.1007/s12665-015-4158-4

[28] Mayer, J. M., Stead, D. "Exploration into the causes of uncertainty in UDEC grain boundary models", Computers and Geotechnics, 82, pp. 110-123, 2017.

https://doi.org/10.1016/j.compgeo.2016.10.003
[29] Gao, F. Q., Kang, H. P. "Effects of pre-existing discontinuities on the residual strength of rock mass - Insight from a discrete element method simulation", Journal of Structural Geology, 85, pp. 40-50, 2016. https://doi.org/10.1016/j.jsg.2016.02.010

[30] Vallejos, J. A., Suzuki, K., Brzovic, A., Ivars, D. M. "Application of Synthetic Rock Mass Modeling to Veined Core-size Samples", International Journal of Rock Mechanics and Mining Sciences, 81, pp. 47-61, 2016. https://doi.org/10.1016/j.ijrmms.2015.11.003

[31] Zhang, Y., Zhao, X. "Characterisation of confinement effect on jointed rock pillars using a Synthetic Rock Mass approach", International Journal for Numerical Analytical Methods in Geomechanics, 40(12), pp. 1690-1711, 2016. https://doi.org/10.1002/nag.2509

[32] Lei, Q. "Characterisation and modelling of natural fracture networks: geometry, geomechanics and fluid flow" Doctoral Dissertation, Imperial College London, 2016. [online] Available at: http://hdl.handle.net/10044/1/42358 [Accessed: 02.04 2019]

[33] Lei, Q., Latham, J.-P., Xiang, J. "Implementation of an Empirical Joint Constitutive Model into Finite-Discrete Element Analysis of the Geomechanical Behaviour of Fractured Rocks", Rock Mechanics and Rock Engineering, 49(12), pp. 4799-4816, 2016. https://doi.org/10.1007/s00603-016-1064-3

[34] Zou, Y., Zhang, S., Ma, X., Zhou, T., Zeng, B. "Numerical investigation of hydraulic fracture network propagation in naturally fractured shale formations", Journal of Structural Geology, 84, pp. 1-13, 2016.

https://doi.org/10.1016/j.jsg.2016.01.004

[35] Wang, X., Jardani, A., Jourde, H., Lonergan, L., Cosgrove, J., Gosselin, O., Massonnat, G. "Characterisation of the transmissivity field of a fractured and karstic aquifer, Southern France", Advances in Water Resources, 87, pp. 106-121, 2016. https://doi.org/10.1016/j.advwatres.2015.10.014

[36] Lei, Q., Wang, X. "Tectonic interpretation of the connectivity of a multiscale fracture system in limestone", Geophysical Research Letters, 43(4), pp. 1551-1558, 2016 https://doi.org/10.1002/2015GL067277

[37] Tsang, C.-F., Neretnieks, I., Tsang, Y. "Hydrologic issues associated with nuclear waste repositories", Water Resources Research, 51(9), pp. 6923-6972, 2015. https://doi.org/10.1002/2015wr017641

[38] Lei, Q., Latham, J.-P., Tsang, C.-F., Xiang, J., Lang, P. "A new approach to upscaling fracture network models while preserving geostatistical and geomechanical characteristics", Journal of Geophysical Research: Solid Earth, 120(7), pp. 4784-4807, 2015. https://doi.org/10.1002/2014jb011736

[39] Brzovic, A., Rogers, S., Webb, G., Hurtado, J. P., Marin, N., Schachter, P., Alvarez, J., Baraona, K. "Discrete fracture network modelling to quantify rock mass pre-conditioning at the El Teniente Mine, Chile", Mining Technology, 124(3), pp. 163-177, 2015. https://doi.org/10.1179/1743286315y.0000000019

[40] Dershowitz, W. S., Curran, B., Einstein, H., LaPointe, P., Shuttle, D., Klise, K. "Discrete feature approach for heterogeneous reservoir production enhancement", National Petroleum Technology Office, Tulsa, Oklahoma, USA, Final report, 2002. 
[41] Zhang, L. "Engineering properties of rocks", 1st ed., ButterworthHeinemann, Oxford, United Kingdom, 2016. https://doi.org/10.1016/C2014-0-02645-7

[42] Zhang, L., Einstein, H. H. "The planar shape of rock joints", Rock Mechanics and Rock Engineering, 43(1), pp. 55-68, 2010. https://doi.org/10.1007/s00603-009-0054-0

[43] Hodgson, R. A. "Classification of structures on joint surfaces", American Journal of Science, 259(7), pp. 493-502, 1961. https://doi.org/10.2475/ajs.259.7.493

[44] Kulander, B. R., Barton, C. C., Dean, S. L. "Application of fractography to core and outcrop fracture investigations", Morgantown Energy Research Center, Morgantown, West Virginia, USA, Rep. METC/SP-79/3, 1979. [online] Available at: https://www.osti.gov/ biblio/5787284 [Accessed: 02.04 2019]

[45] Bahat, D. "Fractographic determination of joint length distribution in chalk", Rock Mechanics and Rock Engineering, 21(1), pp. 79-94, 1988.

https://doi.org/10.1007/bf01019676

[46] Petit, J., Massonnat, G., Pueo, F., Rawnsley, K. "Rapport de forme des fractures de mode 1 dans les roches stratifiees: Une etude de cas dans le Bassin Permian de Lodeve (France)", Bulletin Elf Aquitaine Production, 18, pp. 211-229, 1994. (in French)

[47] Weinberger, R. "Joint nucleation in layered rocks with non-uniform distribution of cavities", Journal of Structural Geology, 23(8), pp. 1241-1254, 2001.

https://doi.org/10.1016/S0191-8141(00)00192-9
[48] Bahat, D., Bankwitz, P., Bankwitz, E. "Preuplift joints in granites: evidence for subcritical and postcritical fracture growth", Geological Society of America Bulletin, 115(2), pp. 148-165, 2003. https://doi.org/10.1130/0016-7606(2003)115<0148:PJIGEF>2.0.CO;2

[49] Savalli, L., Engelder, T. "Mechanisms controlling rupture shape during subcritical growth of joints in layered rocks", Geological Society of America Bulletin, 117(3-4), pp. 436-449, 2005. https://doi.org/10.1130/B25368.1

[50] Daneshy, A. A. "Three-dimensional propagation of hydraulic fractures extending from open holes", In: Proceedings of ASCE 15th Symposium on Rock Mechanics, Custer State Park, South Dakota, United States,1973, pp. 157-179. https://www.osti.gov/biblio/6237187

[51] Moriya, H., Fujita, T., Niitsuma, H., Eisenblätter, J., Manthei, G. "Analysis of fracture propagation behavior using hydraulically induced acoustic emissions in the Bernburg salt mine, Germany", International Journal of Rock Mechanics and Mining Sciences, 43(1), pp. 49-57, 2006. https://doi.org/10.1016/j.ijrmms.2005.04.003

[52] Zhang, L., Einstein, H. H., Dershowitz, W. S. "Stereological relationship between trace length and size distribution of elliptical discontinuities", Geotechnique, 52(6), pp. 419-433, 2002. https://doi.org/10.1680/geot.2002.52.6.419 